\title{
Multiple Inert Gas Elimination Technique
}

National Cancer Institute

\section{Source}

National Cancer Institute. Multiple Inert Gas Elimination Technique. NCI Thesaurus. Code C161408.

A technique that measures the pulmonary exchange of a set of six different inert gases dissolved together in saline (or dextrose) and infused intravenously. The measurements are then used to compute the distribution of ventilation/perfusion ratios that best describes the exchange of the six gases simultaneously. (Wagner PD. The multiple inert gas elimination technique (MIGET). Intensive Care Med. 2008 Jun;34(6):994-1001.) 